Research Article

Open Access

\title{
Parasites associated with Human Immune-Deficiency Virus (HIV) Infection in Assiut University Hospitals, Egypt
}

\author{
Dyab AK ${ }^{1 \star}$, Gaber MA ${ }^{1}$, Hassan $\mathrm{TM}^{1}$, El Kady $\mathrm{AM}^{2}$, Badary $\mathrm{DM}^{3}$ and Mahmoud $\mathrm{HS}^{4}$ \\ ${ }^{\prime}$ Department of Parasitology, Faculty of Medicine, Assiut University, Egypt \\ ${ }^{2}$ Department of Medical Parasitology, Qena Faculty of Medicine, South Valley University, Egypt \\ ${ }^{3}$ Department of Pathology, Faculty of Medicine, Assiut University, Egypt \\ ${ }^{4}$ Department of Tropical Medicine and Gastroenterology, Faculty of Medicine, South Valley University, Qena, Egypt
}

\section{Article Info}

\author{
*Corresponding author: \\ Ahmed Kamal Dyab Haemaei \\ Department of Parasitology \\ Faculties of Medicine \\ Assiut University, Egypt \\ E-mail: ahmedsaf2001@yahoo.com (or) \\ Ahmed2015@aun.edu.eg
}

\begin{abstract}
Received: June 30, 2018
Accepted: July 14, 2018

Published: July 19, 2018
\end{abstract}

Citation: Dyab AK, Gaber MA, Hassan TM, El Kady AM, Badary DM, Mahmoud HS. Parasites associated with Human ImmuneDeficiency Virus (HIV) Infection in Assiut University Hospitals, Egypt. Madridge J Vaccines. 2018; 2(1): 48-53. doi: $10.18689 / \mathrm{mjv}-1000110$

Copyright: (c) 2018 The Author(s). This work is licensed under a Creative Commons Attribution 4.0 International License, which permits unrestricted use, distribution, and reproduction in any medium, provided the original work is properly cited.

Published by Madridge Publishers

\begin{abstract}
Parasitic infections represent a major public health problem in immunocompromised individuals especially in HIV patients.
\end{abstract}

Objective: To throw light on the parasites associated with HIV infection in the local community.

Methods: The present study evaluated patients $10 \mathrm{HIV}$ positive male patients who were admitted at Assiut Tropical Medicine and Assiut University Hospitals, Egypt, between January 2015 and 2016. All of them were diagnosed by the Egyptian ministry of health and received the antiviral treatment. 8 patients were complaining of diarrhea, one patient was Sudanese with two resistant skin ulcers not responding to medical treatment so he came to Assiut tropical hospitals to be diagnosed and treated, one patient, with history of travelling to Uganda, was complaining of irregular fever and jaundice, the last patients was complaining of persistent cough not responding to known antimicrobial medications. So two samples of stool were collected from each patients, together with sputum and a whole blood sample. Skin scrap and biopsy were taken from any existing skin lesions.

Results: 9 out of 10 HIV positive patients had parasitic infections, 5 patients had single parasitic infection while 4 patients had mixed infections with more than one parasite. Parasitic infections were in the form of Cryptosporidium spp (6 patients), Giardia lamblia (4 patients), Leishmania tropica (one patient), Plasmodium falciparum (one patient) and Pneumocystis carinii (one patient).

Conclusions: This is a study of parasitic infections in HIV positive patients were admitted at Assiut Tropical Medicine and Assiut University Hospitals, Egypt. HIV infection has modified the records of parasitic infection as well as outcome of diseases caused by parasites, probably through immune modifications.

Keywords: HIV; Opportunistic parasites; Assiut Tropical Medicine Hospitals; Egypt.

\section{Introduction}

Human immune-deficiency virus (HIV) is a global public health problem [1]. In 2016, about 36.7 million people were living with HIV and it resulted in 1 million deaths [2]. It is estimated that there are 380,000 people infected with HIV/AIDS in the Middle East and North Africa (MENA) [3]. Egypt's first AIDS case was discovered in 1986, since then the number of HIV reported cases are showing a steady increase and are estimated to double nearly every 5 years [3]. According to UNAIDS 2016 statistics, there are about 11,000 people currently living with HIV 
in Egypt [4]. Opportunistic infections (Ols) are one of the existing identified causes that aggravate the condition of HIV-infected patients. Opportunistic parasites play an important role as Ols and are one of the most common causes of morbidity and mortality in HIV/AIDS patients [5].

The association between intestinal parasites and human immunodeficiency virus (HIV) infection is well documented [6]. Among the parasitic opportunistic infections (POIs) cryptosporiosis, isosporidiosis and microsporidiosis are the main enteric/intestinal parasitic infections, while toxoplasmosis and leishmaniasis are the main systemic POIs reported in HIVinfected patients. However, infection with other extracellular parasites in AIDS patients is also related to diarrhoeal disease. Among these parasites, Entamoeba histolytica, Giardia intestinalis and Strongyloides stercoralis are the most important [7].

Leishmaniasis is ranked third in importance among vectorborne infections so it is one of the neglected tropical diseases [8]. Human leishmaniasis is usually classified as visceral (VL), localized or diffuse cutaneous (CL), and mucocutaneous [9]. Leishmaniasis is mainly VL in HIV-infected patients, however, some cases of $C L$ have also been reported from endemic countries in Africa and South America. ${ }^{10,11} \mathrm{CL}$ in HIV-positive patients can become disseminated and is clinically characterized by atypical, multiple, widespread infiltrations of skin lesions; and weak response to classic treatment [10] [11] [12].

Combined HIV and malaria cause more than 2 million deaths each year. HIV increases the risk of malaria infection in adults, especially in those with advanced immunosuppression leading to increased risk of complications and death. Reports also suggest that antimalarial treatment failure may be more common in HIV-infected adults with low CD4-cell counts compared to those not infected with HIV [13].

Pneumocystis carinii, one of the two Pneumocystis species causing human pneumonia. The organism was classified as a protozoan nearly one century ago, in 1988 it was identified as a fungus based on DNA analysis [14]. It has maintained its importance as a pathogen because of its frequent presentation as pneumonia in patients with $\mathrm{T}$ cell mediated immunodeficiency. It is the most important AIDS-defining opportunistic infection in the United States, by contrast, in sub-Saharan Africa the morbidity and mortality in HIV is dominated by tuberculosis [15].

Co infection with HIV and parasites such as malaria, leishmansiasis and intestinal parasites in tropical regions are serious causes of morbidity which if not diagnosed and treated early would cause serious injuries and even death. Thus the detection of these parasites and understanding the importance of the infection would help control the disease as well as better care of these people [16]. So we aimed in this study to detect the parasitic infections in HIV infection in trial to improve quality of life by decreasing the long duration of infection and unresponsiveness to treatment.

\section{Patients and Methods}

The present study took place in Assiut Tropical Medicine Hospitals, between January 2015, 2016. Total of 10 patients were subjected to the present study, all of them were previously diagnosed in the Tropical Medicine Hospitals, Assiut, Egypt, as HIV positive patients and there were reported by the Egyptian ministry of health as HIV positive patients. 7 of them were complaining of diarrhea, one was Sudanese patient complaining of two resistant skin ulcer not responding to the usual antimicrobial treatment so he came to Egypt to seek medical advice. One was an Egyptian male worked in Uganda and complained of irregular fever and jaundice. The last one was complaining of persistent cough not responding to medical treatment by known antibiotics.

\section{Processing of samples}

Two samples of stool were collected from each patients, together with sputum and a whole blood sample. Skin scrap and biopsy were taken from any existing skin lesions. Stool and sputum samples were analyzed by direct microscopy with physiological saline and iodine, after concentration by the formalin ether method coupled with the Ziehl Neelsen Modified technique for the detection of Cryptosporidium sp and Isospora belli and iron haematoxyline for other protozoa [17]. Blood samples were examined by preparation of thin and thick blood films to detect possible parasitic infections. Skin scraps were stained with Geimsa and examined by direct microscopy, skin biopsies were fixed for histopathological examination at Department of Pathology, Faculty of Medicine, Assiut University [18].

Ethical statement: Written consent was obtained from all patients involved in the present study.

\section{Results}

The total number of HIV positive patients involved in the present study was 10 . All of them were males .9 patients were above 35 years old while only one was 25 years old. After examination of all samples obtained from the patients we recognized that 9 of them had parasitic infections. 5 patients had single parasitic infection in the form of Cryptosporidium infection (2 patients), Giardia lamblia (2 patients) and Plasmodium falciparum infection (1 patient). On the other hand 4 patients had mixed infections with both Cryptosporidium and Giardia (2 patients), Pneumocystis carnii and Cryptosporidium (one patient) and Leishmania tropica and Cryptosporidium (one patient). (Table1).

Table 1. data of patients participating in present study

\begin{tabular}{|c|c|c|c|c|c|c|c|}
\hline ษั & 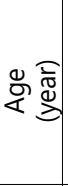 & 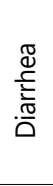 & 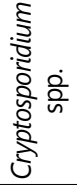 & 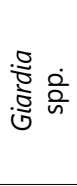 & 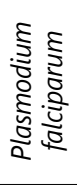 & 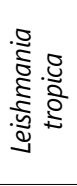 & 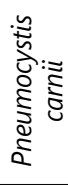 \\
\hline $1^{\text {st }}$ & 29 & + ve & + ve & + ve & & & \\
\hline $2^{\text {nd }}$ & 39 & & & & + ve & & \\
\hline $3^{\text {rd }}$ & 43 & $+\mathrm{ve}$ & $+\mathrm{ve}$ & & & & \\
\hline $4^{\text {th }}$ & 47 & & $+\mathrm{ve}$ & & & & \\
\hline $5^{\text {th }}$ & 41 & $+\mathrm{ve}$ & & + ve & & & \\
\hline $6^{\text {th }}$ & 37 & $+\mathrm{ve}$ & + ve & & & + ve & \\
\hline $7^{\text {th }}$ & 45 & $+\mathrm{ve}$ & & & & & \\
\hline $8^{\text {th }}$ & 1 & + ve & $+\mathrm{ve}$ & $+\mathrm{ve}$ & & & \\
\hline $9^{\text {th }}$ & 36 & + ve & & $+\mathrm{ve}$ & & & \\
\hline $10^{\text {th }}$ & 49 & & $+\mathrm{ve}$ & & & & + ve \\
\hline Total & & 7 & 6 & 4 & 1 & 1 & 1 \\
\hline
\end{tabular}


7 out of 10 HIV positive patients subjected to the study were complaining of watery diarrhea. So Stool examination was carried out twice for each of them which revealed that Cryptosporidiosis and giardiasis were the causative agents of diarrhea in 6 out of 7 cases. On the other hand, Cryptosporidiosis was detected in 2 stool samples for patients who were not complaining of diarrhea (Figure 1).

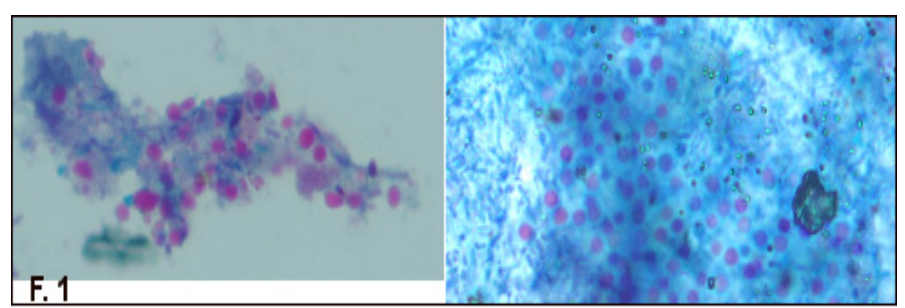

Figure 1. Cryptosporidium oocyst in stool sample stained with stained with Ziehl Neelsen (X1000).

One patient was a HIV positive Sudanese patient presented by 2 destructive skin ulcers; one $7 \times 9 \mathrm{~cm}$ on the dorsum of the left foot, while the other $3 \times 4$ in front of the left leg. Ulcers were resistant o the usual antimicrobial treatment so he came to Egypt for proper diagnosis and treatment of the ulcers. Diagnosis of cutaneous leishmanaiasis was confirmed by stained skin scrap and histopathological examination of biopsies (Figure 2). Serological investigations were done to exclude visceral leishmanaiasis, all were negative.

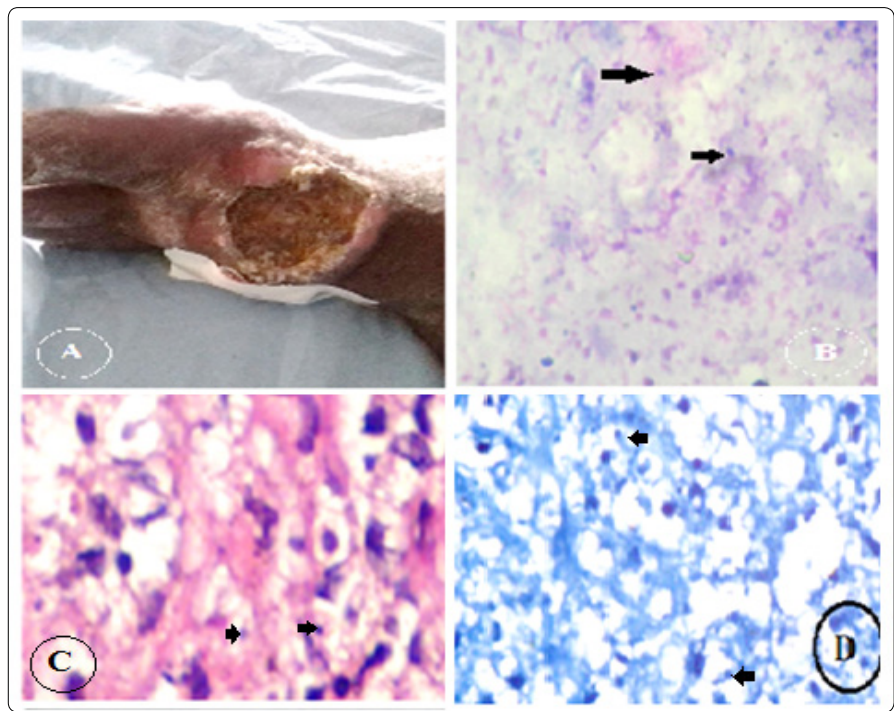

Figure 2. A. Destructive skin ulcer $7 \times 9 \mathrm{~cm}$ on dorsum of left foot of HIV positive patient came to Egypt to receive medical treatment; $B$. Multiple L. tropica amastigote (arrows) in skin scrap stained with Giemsa (X400); C. Infiltrations of lymphocytes and histiocytes with leishman bodies (arrows) stained with H\&E (X400). D. Leishman bodies (arrows) within histiocytes stained with Giemsa (X400)

One patient was admitted to Assiut Tropical Hospital with irregular fever and jaundice with history of travelling to Uganda (African country), Plasmodium infection was suspected and diagnosis was confirmed by thin and thick blood films examination (Figure 3).
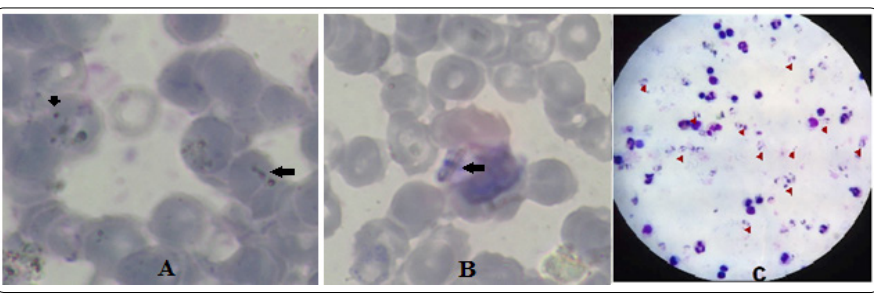

Figure 3. Plasmodium falciparum ring stage and gametocyte (arrows) in thin blood films (A and B respectively) (X400). C: $P$. falciparum ring stage (arrows) in thick blood film stained with Leishman X1000.

One patient was complaining of persistent cough, he was diagnosed as pneumonia and started antibiotic treatment with no response, sputum examination was done and the case was pneumocystis carinii infection. HIV infection was suspected after a long duration of unresponsiveness to treatment and the patient was confirmed serologically to be HIV positive (Figure 4).

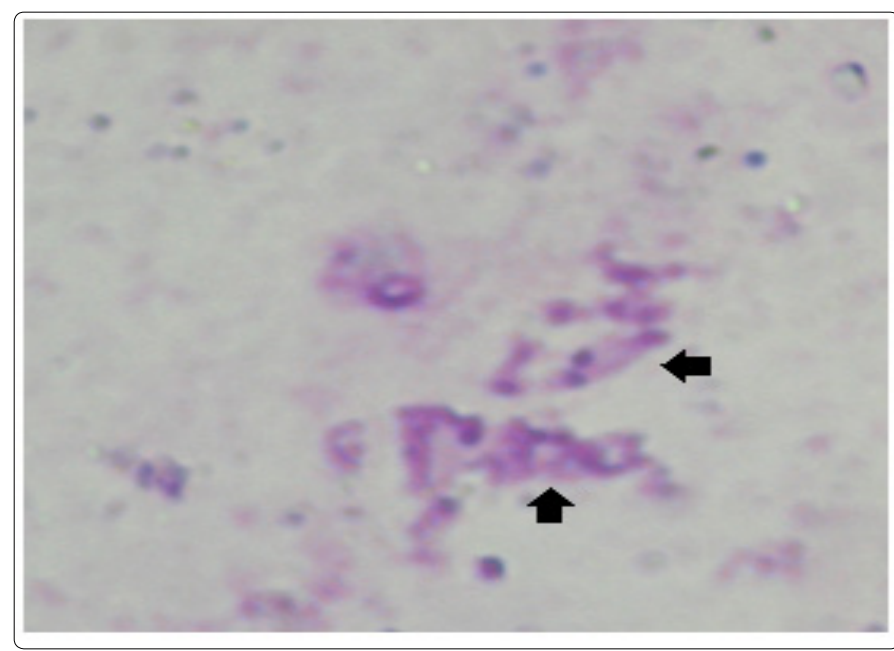

Figure 4. Pneumocystis carnii 8 nucleated cysts in sputum sample stained with stained with Giemsa (X1000).

\section{Discussion}

Number HIV positive patients is raising worldwide, making it a great threat to humans. Parasitic infections are common causes of morbidity and mortality in HIV patients [19]. Prevalence of HIV positive patients in Egypt's is low according to international standards due to conservative culture of local community [20]. To the best of our knowledge this is the first study to assess the prevalence of different parasitic infection among HIV positive patients in Upper Egypt.

The total number of AIDS patients in the present study was 10 patients as the overall prevalence of AIDS in Egypt is less than $0.01 \%$ in the general population [21].

All patients were males, which is in accordance with data acquired by previous surveillance studies done in Egypt regarding high risks groups for HIV infections and common methods of getting infection on the national level [22].

In the present study, stool of all the participants were examined regardless the presence of diarrhea; where 7 out of ten cases were complaining of diarrhea, six of them had 
parasitic infection. The most prevalent intestinal parasites were Cryptosporidium and Giardia spp. respectively. This finding is in agreement with the results reported by several studies in different countries as Ethiopia, Cameroon, Senegal Kenya and Jakarta [23-28].

According to Rao (2016), in HIV patient, the rate of infection with a particular intestinal parasite depends on the endemicity of that parasite in the community [29]. This explain the high prevalence rate of Cryptosporidium followed by Giardia as all conducted survey in the local community had supported the high prevalence of environmental contamination with the 2 intestinal parasites [30].

One HIV patient complained of diarrhea in absence of intestinal parasitic infections which could be explained by anti-retroviral therapy received by the patient as well as the possibility acquisition of intestinal opportunistic bacteria or virus.

Although Egypt is not endemic for leishmanaiasis [31] in the present study we reported one patient represented by disseminated cutaneous leishmanaiasis $(\mathrm{CL})$ in the form of two distractive ulcers without indications of visceral leishmanaiasis.

HIV/leishmaniasis co-infection has been reported in several studies in countries along the Mediterranean basin, mostly were visceral type with Leishmania infantum infection [32]. CL and HIV co-infection was reported from Africa (L. major), Asia (L. tropica), and Latin America (L. braziliensis, L. guyanensis [33].

The co-infection with cutaneous lesions and HIV can be explained by the suppression of cell mediated Immunity (CMI) caused by the virus which is an important factor in human response to leishmanial infection leading to atypical and widespread progression of cutaneous leishmaniasis. Results supported by case reported by several studies. The authors explained the disseminated nature of leishmania lesions through co-infection with HIV which produce cumulative deficiency of the $\mathrm{CMI}$, a key factor for primary protection against infection. Such an HIV-infected patient had an abnormal and severe clinical presentation of $\mathrm{CL}$ in terms of number of ulcers $[34,35]$. However Several arguments suggest that dissemination of lesions is more determined by the virulence of the species involved supported by some publications that reported unusual or rare clinical variants of $\mathrm{CL}$ with or without HIV infection [10,36].

One case of $P$. falciparum was diagnosed in the present study, the patient arrived from a malaria endemic country in Africa (Uganda). The effects of HIV on malaria are well documented: through increasing fever rates, especially for individuals with low CD4 counts or high viral loads [37]. Several studies have found that HIV-1 infection modify the human immune response to Plasmodium falciparum [38, 39]. On the other hand, $P$ falciparum has been shown to stimulate viral replication in case of HIV infection through activation of lymphocytes for production of interleukin- 6 and tumor necrosis factor-alpha and consequently increase the virus load and participate in the progression of HIV disease in patients with malaria infection than in those without and these levels remained higher for up to 10 weeks after treatment [40-42].

In the present study a HIV positive male patient was suffering from resistant and recurrent pneumonia; parasitic examination of sputum revealed pneumocystis carinni. The emerging Pneumocystis spp. Pneumonia was previously the cause of discovery of the Human Immunodeficiency Virus (HIV) in apparently healthy people in the early 80's [43]. Pneumocystis spp. pneumonia still remains a relatively common presentation of uncontrolled HIV, Despite dramatic changes in controls and treatments available for HIV infection $[44,45]$.

Several studies had recorded the prevalence of HIV/ pneumocystis carinii confection in several countries all over the world as South Africa, Malawi, Rwanda, Tanzania; Zambia, Congo, Cote d'Ivoire, South Korea, Taiwan, Thailand and Brazil [46-56]. Such records could not be offered by the current study governed by the low flow rate of patients admitted to the concerning hospitals at time of study.

\section{Conclusion}

The association between parasitic infections and human immunodeficiency virus (HIV) infection is well noticed in the current study. HIV infection has modified the prevalence of parasitic infection as well as outcome of diseases caused by opportunistic parasites, probably through immune activation, sloping the immune response toward T helper-2 immune responses leading to increase host susceptibility. However the effect and association of HIV and some parasites is not clearly understood and need more investigations. So additional researches are needed to investigate the impact of these parasites on the natural history of HIV, potential therapeutic implications, interactions at a cellular and molecular level, and drug interactions between antiretroviral and anti-parasitic medicines.

\section{Author contribution}

Mona Geber conceived the idea. Tasneem Hassan, Asmaa M El-Kady and Dalia Badary contributed to the interpretation of the results. Asmaa M El-Kady, Tasneem Hassan and Hasan $S$ Mahmoud participated in the analysis of results and preparation of the manuscript. All authors red and approved the final version of the manuscript.

\section{References}

1. Kallings LO. The first postmodern pandemic: 25 years of HIV/ AIDS. J. Intern. Med. 2008; 263(3): 218-43. doi: 10.1111/j.1365-2796.2007.01910.x

2. UNAIDS. Fact sheet - Latest statistics on the status of the AIDS epidemic | UNAIDS. Archived from the original on July 13, 2017. Retrieved July 21, 2017.

3. Shawky S, Soliman Ch, Kassak KM, Oraby D, El-Khoury D, Kabore I. Surveillance and Epidemic Profile in the Middle East and North Africa. J Acquir Immune Defic Syndr. 2009; 1: 51(3): S83-S95. doi: 10.1097/QAl.0b013e3181aafd3f

4. UNAIDS. Country Factsheets: EGYPT 2016. 
5. Surekha YA, Shilpa HS, Jeer M, Krishna S. Opportunistic Intestinal Parasites in HIV infected individuals and its Correlation with the CD4 Counts. Int. J. Curr. Microbiol. App. Sci. 2016; 5(2): 279-283

6. Amol Z, Anand P, Anuradha D, Sujata MLB. Opportunistic Intestinal Parasites in HIV Infected Individuals and Its Correlation with the CD4 Counts. RRJMHS. 2014; 3(3): 55-60.

7. Taye B, Desta K, Ejigu S, Dori GU. The magnitude and risk factors of intestinal parasitic infection in relation to Human Immunodeficiency Virus infection and immune status, at ALERT Hospital, Addis Ababa, Ethiopia. Parasitol Int. 2014; 63(3): 550-556. doi: 10.1016/j.parint.2014.02.002

8. Alvar J, Ve'lez ID, Bern C, et al. WHO Leishmaniasis Control Team. Leishmaniasis worldwide and global estimates of its incidence. PloS One. 2012; 7(5): e35671. doi: 10.1371/journal.pone.0035671

9. Dedet JP, Pratlong F. Leishmaniasis. In: Manson P, Cook GC, Zumla A, editors. Manson.s. Tropical diseases. 21st ed. London: Saunders. 2003; 1339-64.

10. Van geertruyden JP. Interactions between malaria and human immunodeficiency virus anno. Clin Microbiol Infect. 2014; 20(4): 278-285. doi: 10.1111/1469-0691.12597

11. Humaira T, Sharmeen A, Mubasshir S. Cutaneous leishmaniasis with HIV.J Coll Phys Surg Pakistan. 2014; 24(Special Supplement 2): S93-5.

12. Mahajan $R$, Das $P$, Isaakidis $P$, et al. Combination treatment for visceral leishmaniasis patients co-infected with human immunodeficiency virus in India. Clin Infect Dis. 2015; 61(8): 1255-62. doi: 10.1093/cid/civ530

13. Jegede $\mathrm{FE}$, Oyeyi $\mathrm{TI}$, Abdulrahman $\mathrm{SA}$, et al. Effect of HIV and malaria parasites co-infection on immune-hematological profiles among patients attending anti-retroviral treatment (ART) clinic in Infectious Disease Hospital Kano, Nigeria. PLoS ONE. 2017; 12(3): e0174233. doi: 10.1371/ journal.pone. 0174233

14. Kelley CF, Checkley W, Mannino DM, Franco-Paredes C, Del Rio C, Holguin F. Trends in hospitalizations for AIDS-associated Pneumocystis jirovecii Pneumonia in the United States (1986 to 2005). Chest; 2009; 136: 190-7.

15. Miller RF, Huang L, Walzer PD. Pneumocystis pneumonia associated with human immunodeficiency virus. Clin Chest Med. 2013; 34(2): 229-41. doi: 10.1016/j.ccm.2013.02

16. Mohandas, Sehgal R, Sud A, Malla N. Prevalence of intestinal parasitic pathogens in HIV-seropositive individuals in Northern India. Jpn J Infect Dis. 2002; 55: 83-4.

17. Assefa Sh, Erko B, Medhin G, Assefa Z, Shimelis T. Intestinal parasitic infections in relation to HIV/AIDS status, diarrhea and CD4 T-cell count. BMC Infectious Diseases. 2009; 9: 155. doi: 10.1186/1471-2334-9-155

18. Surl $\mathrm{CG}, \mathrm{Kim} \mathrm{CH}$. Concurrent response to challenge infections with Cryptosporidium parvum in immunosuppressed C57BL/6N mice. J. Vet. Sci. 2006; 7(1): 47-5.

19. Jain S, Singh AK, Singh RP, Bajaj J, Damle AS. Spectrum of opportunistic and other parasites among HIV/AIDS patients attending a tertiary care hospital. Asian Pacific Journal of Tropical Disease. 2014; 4(6): 480-483. doi: 10.1016/S2222-1808(14)60610-1

20. Boutros S, Skordis J. HIV/AIDS surveillance in Egypt: current status and future challenges. EMHJ. 2010; 16(3).

21. UNAIDS.report on the global AIDS epidemic 2013 [Accessed May 9, 2014]; Global report: UNAIDS 2013.

22. Srikameswaran A. Egypt's fearful gays shy from HIV testing. International reporting project, Paul $\mathrm{H}$. Nitze School of Advanced International Studies of the JohnsHopkinsUniversity[onlinearticle](http://www.internationalreportingproject. org/stories/ detail/575/, accessed 11 August 2009)

23. Adamu $H$, Petros $B$. Intestinal protozoan infections among HIV positive persons with and without Antiretroviral Treatment (ART) in selected ART centers in Adama, Afar and Dire-Dawa, Ethiopia. Ethiop J Health Dev. 2009; 23(2): 133-140.

24. Sarfati C, Bourgeois A, Menotti J, et al. Prevalence of intestinal parasites including microsporidia in human immunodeficiency virus-infected adults in Cameroon: A cross-sectional study. Am J Trop Med Hyg. 2006; 74: 162164.
25. Kiros H, Endalkachew N, Abaineh M, Bizuayehu K, Melaku A. Prevalence of intestinal protozoan infections among individuals living with HIV/AIDS at Felegehiwot Referral Hospital, Bahir Dar, Ethiopia. Int J Infect Dis. 2015; 35: 80-86. doi: 10.1016/j.jijid.2015.04.012

26. Faye $B$, Tine RC, Ndiaye JL, et al. Impact of Intestinal Parasites on Intensity of HIV Infection in Senegal. J Antivir Antiretrovir. 2010; 2(1): 011-012. doi: 10.4172/jaa. 1000015

27. Kipyegen CK, Shivairo RS, Odhiambo RO. Prevalence of intestinal parasites among HIV patients in Baringo, Kenya. Pan Afr Med J. 2012; 13: 37.

28. Kurniawan A, Karyadi T, Dwintasari SW, Yunihastuti E, Djauzi S, Smith HV. Intestinal parasitic infections in HIV/AIDS patients presenting with diarrhea in Jakarta.TransRSocTropMed.2009; 103(9):892-8.doi:10.1016/j.trstmh.2009.02.017

29. Rao RP. Study of opportunistic intestinal parasitic infections in HIV seropositive patients at a tertiary care teaching hospital in Karnataka, India. International Journal of Contemporary Medical Research. 2016; 3(8): 2219-2222.

30. Dyab AK, Yones DY, Sayed DM, Hassan TM. Detection, Enumeration and Viability Evaluation of Giardia Cysts in Water Samples Using Flow Cytometry. Glo. Adv. Res. J. Microbiol. 2015; 4(6): 077-086.

31. Aoun K, Bouratbine A. Cutaneous Leishmaniasis in North Africa: a review. Parasite. 2014; 21: 14. doi: 10.1051/parasite/2014014

32. Rosenthal E, Marty P, Poizot-Martin IJ, et al. Visceral leishmaniasis and HIV-1 co-infection in southern France. Trans. R. Soc. Trop. Med. Hyg. 1995; 89(2): 159-162.

33. Zijlstra EE. PKDL and Other Dermal Lesions in HIV Co-infected Patients with Leishmaniasis: Review of Clinical Presentation in Relation to Immune Responses. PLoS Negl Trop Dis. 2014; 8(11): e3258. doi: 10.1371/journal. pntd.0003258

34. Chaudhary RG, Bilimoria FE, Katare S K. Diffuse cutaneous leishmaniasis: Co-infection with human immunodeficiency virus (HIV). Indian J Dermatol Venereol Leprol. 2008; 74(6): 641-3.

35. Parmentier L, Cusini A, Müller N, et al. Case report: severe cutaneous leishmaniasis in a human immunodeficiency virus patient coinfected with Leishmania braziliensis and its endosymbiotic virus. Am J Trop Med Hyg. 2016; 94(4): 840-843. doi: 10.4269/ajtmh.15-0803

36. Guerra JAO, Coelho LIRC, Pereira FR, Siqueira AM, Ribeiro RL, Almeida $\mathrm{TML}$, et al. American tegumentary leishmaniasis and HIV-AIDS association in a tertiary care center in the Brazilian Amazon. Am J Trop Med Hyg. 2011; 85(3): 524-527. doi: 10.4269/ajtmh.2011.11-0075

37. World Health Organization. Malaria in HIV/AIDS patients. World Health Organization. World malaria report 2015 - regional and country profiles, 2017.

38. Moore JM, Ayisi J, Nahlen BL, Misore A, Lal AA, Udhayakumar V. Immunity to placental malaria. II. Placental antigen-specific cytokine responses are impaired in human immunodeficiency virus-infected women. $J$ Infect Dis. 2000; 182(3): 960-4. doi: 10.1086/315755

39. Van geertruyden JP. Interactions between malaria and human immunodeficiency virus anno. Clin Microbiol Infect. 2014; 20(4): 278-285. doi: 10.1111/1469-0691.12597

40. Froebel K, Howard W, Schafer JR, et al. Activation by malaria antigens renders mononuclear cells susceptible to HIV infection and re-activates replication of endogenous HIV in cells from HIV-infected adults. Parasite Immunol. 2004; 26(5): 213-7. doi: 10.1111/j.0141-9838.2004.00701.x

41. Mermin J, Lule JR, Ekwaru JP. Association between malaria and CD4 cell count decline among persons with HIV. J Acquir Immune Defic Syndr. 2006; 41:129-30.

42. Cunnington A, Riley EM. HIV and Malaria Co-infection. Immunity to Parasitic Infection. 2006; 335-352.

43. Castro JG, Morrison-Bryant M. Management of Pneumocystis Jirovecii pneumonia in HIV infected patients: current options, challenges and future directions. HIV/AIDS - Research and Palliative Care. 2010; 2: 123-134.

44. Kling HM, Shipley TW, Guyach S, Tarantelli R, Morris A, Norris KA Trimethoprim- sulfamethoxazole treatment does not reverse obstructive pulmonary changes in pneumocystis colonized nonhuman primates with HIV infection. J Acquir Immune Defic Syndr. 2014; 65(4): 381-9. doi: 10.1097/QAI.0000000000000007 
45. Fauchier T, Hasseine L, Gari-Toussaint M, Casanova V, Marty PM, Pomares C. Detection of Pneumocystis jirovecii by quantitative PCR to differentiate colonization and pneumonia in immunocompromised HIV-positive and HIV-negative patients. J Clin Microbiol. 2016; 54: 1487-1495. doi: 10.1128/ JCM.03174-15

46. Zar HJ, Dechaboon A, Hanslo D, Apolles P, Magnus KG, Hussey G. Pneumocystis carinii pneumonia in South African children infected with human immunodeficiency virus. Pediatr Infect Dis J. 2000; 19(7): 603-607. doi: 10.1097/00006454-200007000-00004

47. Graham SM, Mtitimila El, Kamanga HS, Walsh AL, Hart CA, Molyneux ME. Clinical presentation and outcome of Pneumocystis carinii pneumonia in Malawian children. Lancet. 2000; 355(9201): 369-373. doi: 10.1016/S01406736(98)11074-7

48. Batungwanayo J, Taelman $\mathrm{H}$, Lucas SB, et al. Pulmonary disease associated with HIV in Kigali, Rwanda. Am J RespirCrit Care Med. 1994; 149(6): 1591-6. doi: 10.1164/ajrccm.149.6.8004318

49. Atzori C, Bruno A, Chichino G, Gatti S, Scaglia M. Pneumocystis carinii pneumonia and tuberculosis in Tanzanian patients infected with HIV. Trans R Soc Trop Med Hyg. 1993; 87(1): 55-6.
50. Machiels G, Urban MI. Pneumocystis carinii as a cause of pneumonia in HIV-infected patients in Lusaka, Zambia. Trans R Soc Trop Med Hyg. 1992; 86(4): 399-400.

51. Carme B, Mboussa J, Andzin M, Mbouni E, Mpele P, Datry A. Pneumocystis carinii is rare in AIDS in Central Africa. Trans $R$ Soc Trop Med Hyg. 1991; 85(1): 80-5.

52. Lucas $S B$, Peacock $C S$, Hounnou $A$, et al. Disease in children infected with HIV in Abidjan, Cote d'Ivoire. BMJ. 1996; 312(7027): 335-38.

53. Oh MD, Park SW, Kim HB, et al. Spectrum of opportunistic infections and malignancies in patients with human immunodeficiency virus infection in South Korea. Clin Infect Dis. 1999; 29(6): 1524-8. doi: 10.1086/313516

54. Hsiao $\mathrm{CH}$, Huangm $\mathrm{SH}$, Huang SF, et al. Autopsy findings on patients with AIDS in Taiwan. J Microbiollmmunol Infect. 1997; 30(3): 145-59.

55. Lumbiganon $\mathrm{P}$, Kosalaraksa $\mathrm{P}$, Loapaiboon $\mathrm{M}$. Survival of children with AIDS: experience in a university hospital in northeast Thailand. J Med Assoc Thai. 2000; 83: 652-6.

56. Michalany J, Mattos AL, Michalany NS, et al. Acquired immune deficiency syndrome in Brazil: necropsy findings. Ann Pathol. 1987; 7: 15-24. 